\title{
Changes in cardiac function and hemodynamics during robot-assisted laparoscopic prostatectomy with steep head-down tilt: a prospective observational study
}

\author{
Naomi Ono, Junko Nakahira* ${ }^{*}$, Shoko Nakano, Toshiyuki Sawai and Toshiaki Minami
}

\begin{abstract}
Objective: Robot-assisted laparoscopic prostatectomy requires the patient to be placed in a steep head-down tilt. The aim of our study was to investigate changes in cardiac index and left ventricular end-diastolic volume in a steep had-down tilt. This is a prospective observational study. We investigated the influence of steep head-down tilt on cardiac function and hemodynamics without fluid restriction in 12 men of American Society of Anesthesiologists physical status I-II undergoing robot-assisted laparoscopic prostatectomy. We measured left ventricular ejection fraction, left ventricular end-diastolic volume and cardiac index by transesophageal echocardiography, cardiac index using a FloTrac ${ }^{\circledR}$ sensor, heart rate and arterial blood pressure, before and 5 min after tilting the operating table.

Results: The following variables changed significantly after tilting and establishment of the pneumoperitoneum: left ventricular ejection fraction (before 62.5\%, after 55.5\%; $\mathrm{P}=0.040$ ), systolic blood pressure (before $116 \mathrm{mmHg}$, after $128 \mathrm{mmHg} ; \mathrm{P}=0.001$ ) and diastolic blood pressure (before $59 \mathrm{mmHg}$, after $70 \mathrm{mmHg} ; \mathrm{P}=0.002$ ). There were no significant changes in cardiac index or left ventricular end-diastolic volume measured by transesophageal echocardiography, or cardiac index by FloTrac ${ }^{\circledR}$ sensor. Left ventricular ejection fraction decreased, whereas cardiac index and left ventricular end-diastolic volume did not change, indicating that steep head-down tilt and pneumoperitoneum during robot-assisted laparoscopic prostatectomy did not greatly influence cardiac function.

This study was registered as a clinical study with the Japanese Official Clinical Trial Registry (Trial Registration Number JMA-IIA00158 on 7th January, 2014)
\end{abstract}

Keywords: Robot-assisted laparoscopic prostatectomy, Steep head-down tilt, Transesophageal echocardiography

\section{Introduction}

Robot-assisted techniques have gained popularity because they overcome several of the shortcomings of conventional laparoscopic techniques. The problems associated with robotic prostatectomy are a consequence of four main factors: the steep Trendelenburg position of the patient, the insufflation of carbon dioxide to produce

*Correspondence: ane052@osaka-med.ac.jp Department of Anesthesiology, Osaka Medical College,

2-7 Daigaku-machi, Takatsuki, Osaka 569-8686, Japan a pneumoperitoneum, spatial restrictions because of the bulk of the equipment set over the patient, and the possibility of unexpected visceral injury or blood loss [1].

A few cases of cardiopulmonary deterioration, evidenced by pulmonary edema, pulmonary embolism and worsening of mitral regurgitation, have been reported during this procedure [2-4]. We investigated the changes in hemodynamic parameters and cardiac function during robot-assisted laparoscopic prostatectomy (RALP) without fluid restriction. 


\section{Main text Methods}

The study protocol was approved by the Ethics Committee of Osaka Medical College (Reference Number 1339), and all participants provided written informed consent. This study was registered as a clinical study with the Japanese Official Clinical Trial Registry (Trial Registration Number JMA-IIA00158). Twelve men scheduled for RALP under general anesthesia were assessed in this prospective observational study. All subjects were selected after routine screening and all met the criteria for American Society of Anesthesiologists (ASA) physical status classification I-II. Routine preoperative evaluation included electrocardiography, chest radiographs, hematocrit and a screening chemistry panel to aid in identifying underlying myocardial ischemia, chronic obstructive pulmonary disease, anemia and hyperglycemia. Patients with cardiac disease, including dysrhythmia and coronary artery disease, and those with moderate or severe obstructive pulmonary disease, did not meet the criteria for this study. All RALP procedures were performed on the same ALPHAMAXX ${ }^{\circledR}$ operating table, (MAQUET Holding B.V. and Co. KG, Rastatt, Germany) and with the da Vinci ${ }^{\circledR}$ Surgical System (Intuitive Surgical, Sunnyvale, CA, USA).

No premedication was given. Anesthesia was induced with propofol $1.5-2.0 \mathrm{mg} / \mathrm{kg}$, inhaled sevoflurane $3.0 \%$ and remifentanil $0.3-0.5 \mu \mathrm{g} / \mathrm{kg} / \mathrm{min}$, and maintained with remifentanil $0.1-0.3 \mu \mathrm{g} / \mathrm{kg} / \mathrm{min}$ and inhaled sevoflurane $1.5 \%$. Rocuronium $0.5 \mathrm{mg} / \mathrm{kg}$ was used to facilitate orotracheal intubation and was repeated as needed for muscle relaxation. The patients were intubated with a cuffed endotracheal tube and their lungs mechanically ventilated in volume-controlled mode with a mixture of oxygen and air: the fraction of inspired oxygen was 0.4, the tidal volume was $7 \mathrm{~mL} / \mathrm{kg}$ predicted ideal body weight and positive end-expiratory pressure (PEEP) of $5 \mathrm{~cm} \mathrm{H}_{2} \mathrm{O}$ was provided. After induction of anesthesia, ventilation was adjusted to achieve an end-tidal carbon dioxide tension of 32-36 mmHg. If oxygen saturation measured by pulse oximetry was less than $97 \%$, the tidal volume was increased to $8.5 \mathrm{~mL} / \mathrm{kg}$, and the PEEP increased. No changes were made in ventilator settings between beforeand post-tilting measurements. At least $1000 \mathrm{~mL}$ of intravenous crystalloid or colloid was infused before the patient was placed in the steep head-down tilt.

Patients' clinical records were reviewed and relevant patient background information, including age, body mass index and intraoperative variables, were collected. Pre-tilting measurements were performed under stable anesthesia and steady-state conditions with the patients in the horizontal position before surgery began. Post-tilting variables were measured $5 \mathrm{~min}$ after the patients had been positioned in a $28^{\circ}$ head-down tilt and a pneumoperitoneum of 12-15 $\mathrm{mmHg}$ had been achieved. Measured variables comprised left ventricular end-diastolic volume (LVEDV), left ventricular ejection fraction (LVEF) and cardiac index $(\mathrm{CI})$ by transesophageal echocardiography (TEE), blood pressure (BP) in the radial artery, CI using a FloTrac ${ }^{\circledR}$ sensor and Vigileo ${ }^{\circledR}$ monitor (Edwards Lifesciences, Irvine, CA, USA), central venous blood oxygen saturation $\left(\mathrm{ScrO}_{2}\right)$ using a PreSep ${ }^{\circledR}$ central venous oximetry catheter (Edwards Lifesciences), and heart rate and regional hemoglobin oxygen saturation $\left(\mathrm{rSO}_{2}\right)$ using an INVOS $^{\mathrm{TM}} 5100 \mathrm{C}$ cerebral/somatic oximeter (Medtronic Minimally Invasive Therapies, Minneapolis, MN, USA). A multiplane TEE probe, $\mathrm{iE} 33^{\circledR} \mathrm{X} 7-2 \mathrm{t}$ transducer (Philips N.V., Amsterdam, the Netherlands) was introduced into the esophagus after induction of anesthesia. The LVEF was calculated in the mid-esophageal four-chamber view, whereas the left ventricular end-diastolic and endsystolic areas were measuring using an iE33 ultrasound system using the modified Simpson's method (Philips). Urine output was determined by insertion of a urinary catheter during the surgical procedure and a proportion of the urine was included in the total blood loss.

Preliminary data for LVEDV recorded in a pilot study of nine patients undergoing RALP were $125.8 \pm 25.2 \mathrm{~mL}$ (mean \pm standard deviation [SD]) before tilting and $116.6 \pm 27.4 \mathrm{~mL}$ after tilting. The SD was therefore considered to be 25.2 and the expected difference in LVEDV $10 \mathrm{~mL}$. Sample size calculation informed by these data, with an $\alpha$ error level of $5 \%$ and an expected pre-and posttilting difference in LVEDV of $10 \mathrm{~mL}$, found that $60 \mathrm{sub}$ jects would be required to obtain an $80 \%$ power goal for comparing pre- and post-head down tilt. However, the study was stopped prematurely after 12 subjects had been enrolled as the researchers moved to the different institutes. The pre- and post-tilting measurements obtained were compared using Wilcoxon signed-rank tests, with $\mathrm{P}<0.05$ considered statistically significant. Data are presented as medians with interquartile ranges. All statistical analyses were performed using GraphPad Prism 6 software (GraphPad Software, La Jolla, CA, USA).

\section{Results}

We obtained data from 12 patients. There were no episodes of severe bradycardia. A crystalloid was infused in all cases and an additional $500 \mathrm{~mL}$ of colloid was infused in three cases. There were no instances of uncontrollable hemorrhage or respiratory disorder intra- or post-operatively.

Relevant patient characteristics and intraoperative variables are shown in Table 1. Comparison of measured variables before and after tilting and establishment of the pneumoperitoneum showed significant changes in 
Table 1 Relevant patient characteristics and intraoperative variables

\begin{tabular}{lc}
\hline Variable & Data, $\mathbf{n}=\mathbf{1 2}$ (interquartile range) \\
\hline Patient background & $67(65-68)$ \\
Age (years) & $165.3(160.3-168.8)$ \\
Height $(\mathrm{cm})$ & $71.6(64.3-76.7)$ \\
Body weight $(\mathrm{kg})$ & $1.78(1.70-1.85)$ \\
Body surface area $\left(\mathrm{m}^{2}\right)$ & $26.2(23.6-28.5)$ \\
Body mass index $\left(\mathrm{kg} / \mathrm{m}^{2}\right)$ & \\
Intraoperative variables & $304.0(290.8-311.5)$ \\
Anesthetic time $(\mathrm{min})$ & $204.5(195.5-234.0)$ \\
Operation time $(\mathrm{min})$ & $173.0(152.0-185.0)$ \\
Pneumoperitoneum time $(\mathrm{min})$ & $2750(2175-3375)$ \\
Volume infused $(\mathrm{mL})$ & $105(40-298)$ \\
Volume of urine $(\mathrm{mL})$ & $200(100-587.5)$ \\
Volume of blood loss $(\mathrm{mL})$ &
\end{tabular}

Data are expressed as medians with interquartile ranges

median LVEF (before 62.5\%, after 55.5\%; $\mathrm{P}=0.040$ ), systolic BP (before $116 \mathrm{mmHg}$, after $128 \mathrm{mmHg} \mathrm{P}=0.001$ ), diastolic $\mathrm{BP}$ (before $59 \mathrm{mmHg}$, after $70 \mathrm{mmHg}$; $\mathrm{P}=0.002$ ) and $\mathrm{rSO}_{2}$ (left: before $64 \%$, after $67 \%, \mathrm{P}=0.034$; right: before $65 \%$, after $70 \%, \mathrm{P}=0.003$ ) (Table 2). There were no significant changes in median LVEDV measured by TEE (before $124.0 \mathrm{~mL}$, after $119.5 \mathrm{~mL}$; $\mathrm{P}=0.955$ ), CI measured by TEE (before $2.5 \mathrm{~L} / \mathrm{min} / \mathrm{m}^{2}$, after $2.2 \mathrm{~L} / \mathrm{min} /$ $\mathrm{m}^{2} ; \mathrm{P}=0.143$ ), CI by FloTrac ${ }^{\circledR}$ sensor (before $2.3 \mathrm{~L} / \mathrm{min} /$ $\mathrm{m}^{2}$, after $2.3 \mathrm{~L} / \mathrm{min} / \mathrm{m}^{2}, \mathrm{P}=0.350$ ) or $\mathrm{SvcO}_{2}$ (before $83 \%$, after $85 \%, \mathrm{P}=0.200$ ).

\section{Discussion}

We examined changes in circulatory status by measuring hemodynamic and cardiac function brought about by $28^{\circ}$ head-down tilting and establishment of the pneumoperitoneum in men undergoing RALP. We found that headdown tilt and pneumoperitoneum significantly decreased LVEF but that LVEDV and CI measured by TEE, and CI measured with a FloTrac ${ }^{\circledR}$ sensor, did not change. These findings indicate that a steep head-down tilt and pneumoperitoneum during RALP did not greatly influence cardiac function in our study patients.

Augmented venous return may result in an increase in right ventricular filling. The high inspiratory pressures required for mechanical ventilation following positioning of a patient in a steep head-down tilt and creation of a pneumoperitoneum reportedly increase right ventricular afterload, reducing right ventricular ejection and consequently increasing right ventricular volumes [2]. A steep Trendelenburg position and pneumoperitoneum may also increase left ventricular afterload because blood flow to the left ventricle is augmented by the increase in
Table 2 Comparison of circulatory variables

\begin{tabular}{|c|c|c|c|}
\hline Variable & Pre-tilting (range) & $\begin{array}{l}\text { Post-tilting } \\
\text { (range) }\end{array}$ & $P$ value \\
\hline \multicolumn{4}{|c|}{ Basic hemodynamic variables } \\
\hline Heart rate (/min) & $60.0(56.3-64.5)$ & $59.0(53.3-64.5)$ & 0.148 \\
\hline $\begin{array}{l}\text { Systolic BP } \\
(\mathrm{mmHg})\end{array}$ & $116.0(101.3-125.0)$ & $127.5(110.0-130.0)$ & 0.001 \\
\hline $\begin{array}{l}\text { Diastolic BP } \\
(\mathrm{mmHg})\end{array}$ & $59.0(55.0-72.5)$ & $70.0(61.0-80.0)$ & 0.002 \\
\hline $\mathrm{ET}-\mathrm{CO}_{2}(\mathrm{mmHg})$ & $36.0(33.3-38.5)$ & $37.5(34.3-38.8)$ & 0.080 \\
\hline $\mathrm{SpO}_{2}(\%)$ & $100(98.5-100)$ & $99.5(99.0-100)$ & 0.625 \\
\hline \multicolumn{4}{|l|}{ FloTrac ${ }^{\circledR}$ sensor data } \\
\hline $\begin{array}{c}\text { Cardiac index } \\
\left(\mathrm{L} / \mathrm{min} / \mathrm{m}^{2}\right)\end{array}$ & $2.28(2.17-2.55)$ & $2.30(2.20-2.85)$ & 0.350 \\
\hline \multicolumn{4}{|l|}{ TEE data } \\
\hline $\begin{array}{l}\text { Cardiac output } \\
(\mathrm{L} / \mathrm{min})\end{array}$ & $4.3(3.8-5.1)$ & $4.0(3.1-4.7)$ & 0.129 \\
\hline $\begin{array}{c}\text { Cardiac index } \\
\left(\mathrm{L} / \mathrm{min} / \mathrm{m}^{2}\right)\end{array}$ & $2.5(2.2-3.0)$ & $2.2(1.7-2.8)$ & 0.143 \\
\hline $\begin{array}{l}\text { Ejection fraction } \\
(\%)\end{array}$ & $62.5(57.0-67.3)$ & $55.5(50.5-60.8)$ & 0.040 \\
\hline $\begin{array}{l}\text { Stroke volume } \\
(\mathrm{mL})\end{array}$ & $75.0(61.0-89.5)$ & $79.0(59.3-87.0)$ & 0.235 \\
\hline \multicolumn{4}{|c|}{ PreSep ${ }^{\circledR}$ catheter data } \\
\hline $\mathrm{ScvO}_{2}(\%)$ & $83.0(78.3-86.8)$ & $85.0(79.5-87.5)$ & 0.195 \\
\hline \multicolumn{4}{|c|}{ INVOS $^{\mathrm{TM}}$ oximeter data } \\
\hline Left rSO $2(\%)$ & $64.0(59.8-75.5)$ & $66.5(61.8-79.3)$ & 0.034 \\
\hline Right $\mathrm{rSO}_{2}(\%)$ & $64.5(61.8-68.5)$ & $69.5(64.8-73.5)$ & 0.003 \\
\hline
\end{tabular}

Data are expressed as medians with interquartile ranges

$E T-\mathrm{CO}_{2}$ end-tidal carbon dioxide, $\mathrm{LVEDV}$ left ventricular end-diastolic volume, $r \mathrm{SO}_{2}$ regional saturation of oxygen, $\mathrm{SpO}_{2}$ percutaneous oxygen saturation, $\mathrm{ScVO}_{2}$ central venous blood oxygen saturation

right ventricular output. Pulmonary artery wedge pressure is reportedly more than twofold that of initial values [5]. Although left ventricular end-diastolic pressure (LVEDP) provides the most useful information concerning left ventricular afterload, we did not measure this in our study. We found no significant changes in cardiac output $(\mathrm{CO})$ or CI measured by TEE and FloTrac ${ }^{\circledR}$ sensing; both these variables reflect stroke volume and heart rate, neither of which changed. Ejection fraction is determined by LVEDV and left ventricular end-systolic volume. Although stroke volume and LVEDV did not change, LVEF decreased in our cohort, suggesting that the decrease in LVEF was not clinically significant. Rosendal et al. reportedly identified no changes in cardiac contractility throughout RALP procedures, although the afterload increased more than twofold [6, 7]. Several studies have reported values for $\mathrm{CO}$ and $\mathrm{CI}$ after steep head-down tilting for RALP, CI having been reported differently in different studies. Haas et al. reported an increase in CO, Lester et al. and Rosendal et al. reported no changes in $\mathrm{CI}$, whereas Darlong et al., Danic et al. 
and Felabella et al. all reported decreases in CI [2, 6, 8, 9]. Age, cardiovascular status, obesity and volume status may influence these variables [1]. According to a study in which a fluid challenge was administered, arterial elastance is an important influence on mean arterial pressure (MAP) response to head-down tilting and creation of a pneumoperitoneum [10]. We did not restrict fluids in our study, nor did we measure LVEDP, which is an important variable. Given that we did not restrict volume of infused fluids, a high LVEDP may have helped us to identify fluid overloading. We were unable to measure LVEDP or left atrial pressure in our patients as we did not catheterize the pulmonary artery, a substantially more invasive means of measuring $\mathrm{CO}$ and $\mathrm{CI}$. We also did not measure pulmonary venous flow velocity pattern to make assessments of changes in LVEDP.

Several authors have recommended fluid restriction during radical prostatectomy to facilitate adequate visualization of the surgical field and minimize blood loss, because this procedure may induce adverse respiratory, cardiovascular, and neurophysiological changes such as severe laryngeal edema, respiratory complications and brachial plexus injury $[10,11]$. In contrast, some surgeons have insisted that restricted fluid management (defined as $<2000 \mathrm{~mL}$ for each case) causes postoperative oliguria [12], and the surgeons in our institute judge that intraor postoperative hypovolemia may result in more serious adverse events than an obscured operative field during bladder neck transection. The policy of our institution is therefore not to restrict intravenous fluids during RALP.

A patient with undiagnosed mild mitral valve insufficiency reportedly experienced transitory exacerbation of that insufficiency during RALP [2]. A possible explanation for this is increased left ventricular after- and pre-loads; however, the degree of mitral insufficiency reverted to the initial status after the patient was repositioned [2].

In our study, the percutaneous $\mathrm{rSO}_{2}$ increased with head-down tilt, consistent with other studies [10, 13]. We also measured $\mathrm{ScvO}_{2}$, which did not change. These findings support the conclusion that the effects of steep head-down tilt and pneumoperitoneum on the cerebral circulation are relatively small. Using second-generation near infrared spectroscopy, Kalmar et al. recently reported that cerebral perfusion pressure was maintained above the lower threshold of cerebral autoregulation during RACP, likely because of simultaneous increases in MAP and central venous pressure [10].

\section{Conclusions}

We found that LVEF decreased after steep head-down tilting and establishment of pneumoperitoneum for
RALP, whereas CI and LVEDV measured by TEE, and CI measured by FloTrac ${ }^{\circledR}$, did not change. These findings indicate that the steep head-down tilt and pneumoperitoneum during RALP did not greatly influence cardiac function in our cohort. Additionally, assessment of CI with TEE did not provide more useful information concerning cardiac function than was provided by FloTrac ${ }^{\circledR}$ in these patients.

\section{Limitations}

The limitations of our trial include its small size, the criteria for patient selection and the use of volume-controlled ventilation during RALP. Different settings for tidal volume and PEEP, or pressure-controlled ventilation, may have produced different results. In our institute, only patients who meet the criteria for ASA I-II undergo RALP. Because a pneumoperitoneum and steep Trendelenburg position are well tolerated by individuals with normal cardiac function, further clinical trials are required to evaluate those with cardiac or valve dysfunction or high pulmonary vascular pressure undergoing this procedure.

\section{Abbreviations}

BP: blood pressure; $\mathrm{Cl}$ : cardiac index; $\mathrm{CO}$ : cardiac output; $\mathrm{CO}_{2}$ : carbon dioxide; LVEDP: left ventricular end-diastolic pressure; LVEDV: left ventricle end-diastolic volume; LVEF: left ventricular ejection fraction; MAP: mean arterial pressure; PEEP: positive end-expiratory pressure; RALP: robot-assisted laparoscopic prostatectomy; $\mathrm{rSO}$ : regional saturation of oxygen; $\mathrm{ScvO}_{2}$ : central venous blood oxygen saturation; TEE: transesophageal echocardiography.

\section{Authors' contributions}

$\mathrm{NO}$ and JN designed the study, interpreted the data and drafted the manuscript. SN corrected the data and reviewed the manuscript. TS confirmed the analysis of the data and reviewed the manuscript. TM designed the study and reviewed the manuscript. All authors read and approved the final manuscript.

\section{Acknowledgements \\ None.}

Competing interests

The authors declare that they have no competing interests.

\section{Availability of data and materials}

The datasets during and/or analysed during the current study available from the corresponding author on reasonable request.

\section{Consent for publication}

Not applicable.

\section{Ethics approval and consent to participate}

The study protocol was approved by the Ethics Committee of Osaka Medical College (Reference Number 1339); all participants provided written informed consent.

Funding

None.

\section{Publisher's Note}

Springer Nature remains neutral with regard to jurisdictional claims in published maps and institutional affiliations. 
Received: 23 August 2016 Accepted: 22 July 2017

Published online: 28 July 2017

\section{References}

1. Baltayian S. A brief review: anesthesia for robotic surgery. J Robot Surg. 2008;2:59-66.

2. Haas S, Haese A, Goetz AE, Kubitz JC. Haemodynamics and cardiac function during robotic-assisted laparoscopic prostatectomy in steep Trendelenburg position. Int J Med Robot. 2011;7:408-13.

3. Hong JY, Oh YJ, Rha KH, Park WS, Kim YS, Kil HK. Pulmonary edema after da Vinci-assisted laparoscopic radical prostatectomy: a case report. J Clin Anesth. 2010;22:370-2.

4. Secin FP, Jiborn T, Bjartell AS, Fournier G, Salomon L, Abbou CC, et al. Multi-institutional study of symptomatic deep venous thrombosis and pulmonary embolism in prostate cancer patients undergoing laparoscopic or robot-assisted laparoscopic radical prostatectomy. Eur Urol. 2008;53:134-45.

5. Gainsburg DM. Anesthetic concerns for robotic-assisted laparoscopic radical prostatectomy. Minerva Anestesiol. 2012;78:596-604.

6. Rosendal C, Markin S, Hien MD, Motsch J, Roggenbach J. Cardiac and hemodynamic consequences during capnoperitoneum and steep Trendelenburg positioning: lessons learned from robot-assisted laparoscopic prostatectomy. J Clin Anesth. 2014;26:383-9.
7. Lestar M, Gunnarsson L, Lagerstrand L, Wiklund P, Odeberg-Wernerman S. Hemodynamic perturbations during robot-assisted laparoscopic radical prostatectomy in $45^{\circ}$ Trendelenburg position. Anesth Analg. 2011;113:1069-75.

8. Darlong V, Kunhabdulla NP, Pandey R, Chandralekha Punj J, Garg R, et al. Hemodynamic changes during robotic radical prostatectomy. Saudi J Anaesth. 2012:6:213-8.

9. Falabella A, Moore-Jeffries E, Sullivan MJ, Nelson R, Lew M. Cardiac function during steep Trendelenburg position and $\mathrm{CO}_{2}$ pneumoperitoneum for robotic-assisted prostatectomy: a trans-oesophageal Doppler probe study. Int J Med Robot. 2007:3:312-5.

10. Kalmar AF, Foubert L, Hendrickx JF, Mottrie A, Absalom A, Mortier EP, et al. Influence of steep Trendelenburg position and $\mathrm{CO}_{2}$ pneumoperitoneum on cardiovascular, cerebrovascular, and respiratory homeostasis during robotic prostatectomy. Br J Anaesth. 2010;104:433-9.

11. Casati A, Spreafico E, Putzu M, Fanelli G. New technology for noninvasive brain monitoring: continuous cerebral oximetry. Minerva Anestesiol. 2006:72:605-25.

12. Baltayian S. A brief review: anesthesia for robotic prostatectomy. J Robot Surg. 2008;2:59-66.

13. Park EY, Koo BN, Min KT, Nam SH. The effect of pneumoperitoneum in the steep Trendelenburg position on cerebral oxygenation. Acta Anaesthesio Scand. 2009;53:895-9.

\section{Submit your next manuscript to BioMed Central and we will help you at every step:}

- We accept pre-submission inquiries

- Our selector tool helps you to find the most relevant journal

- We provide round the clock customer support

- Convenient online submission

- Thorough peer review

- Inclusion in PubMed and all major indexing services

- Maximum visibility for your research

Submit your manuscript at www.biomedcentral.com/submit 